\title{
Helios, voz de un renacimiento hispánico
}

$F^{L}$ comienzo del siglo xx fué para España e Hispanoamérica algo más que un punto cronológico en el desarrollo de su historia literaria. Después del agotamiento de las últimas décadas del siglo XIx, se sentía ya una nueva fuerza vital que comenzaba a transformar el espíritu de las letras hispánicas. Si bien el fenómeno se había anunciado algunos años antes de que el siglo XIX llegara a su fin $-\mathrm{y}$ en Hispanoamérica antes que en España-, eso no fué sino augurio de la renovación que en los primeros años del siglo $\mathrm{xx}$ hubo de alcanzar vigor $\mathrm{y}$ plenitud. El espíritu nuevo era como un viento fresco que comenzara a soplar, avivando las cenizas de la inspiración muerta, sacándoles primero débil luz rojiza, luego llamitas fluctuantes, y por fin flechas de lumbre pura disparadas hacia lo infinito.

Para España fué una época literaria como ninguna que se había conocido después del Siglo de Oro; para Hispanoamérica fué la madurez literaria por primera vez alcanzada, y significó para ambas un estrechamiento de lazos culturales, no rotos, pero sí, aflojados, desde las guerras de independencia. Si Rubén Darío y otros americanos se nutrían mucho de los clásicos españoles, la nueva generación de escritores españoles leía con entusiasmo las obras del propio Darío, las de Silva, de Rodó y otros. Un poeta nicaragüense contaba entre su séquito los jóvenes más talentosos de una España resurgente.

La historia más viva y más fiel que se pudiera encontrar de este período es la que está escrita en las páginas de una de sus revistas literarias: Helios. Muy pocos deben de ser los ejemplares 
de esta revista que se han conservado. La vida de Helios fué corta; pasó por su tiempo como un meteoro, breve pero deslumbrante. El primer número se publicó en abril de 1903; el último, en febrero de 1904. Once números, nada más, pero son éstos como un inventario de los valores literarios más altos del mundo hispánico de esos días. En ellos se revive uno de los momentos más emocionantes de la historia literaria de los países de habla española.

La fundación de Helios la cuenta uno de sus mismos fundadores, Juan Ramón Jiménez, en una carta a Rubén Darío. La carta, escrita en 1902, dice en parte lo siguiente:

Querido maestro: Cinco amigos míos, y yo vamos a hacer una revista literaria seria y fina: algo como el Mercure de Fran$c e$ : un tomo mensual de 150 páginas, muy bien editado. Nosotros mismos costeamos la revista; así, puedo decir a usted que vivirá mucho tiempo; es cosa madura y muy bien calculada. Nada de lucro; vamos a hacer una revista de ensueño; trabajaremos por el gran placer de trabajar. En fin, basta esta afirmación: es una cosa seria.

Yo agradecería infinitamente que nos enviara algo de lo que haga o tenga hecho: versos, prosa. $\mathrm{Y}$, además, que nos concediera usted permiso para copiar algunas cartas o fragmentos de las cartas que usted escribe para La Nación. ${ }^{1}$

Darío, estando ya en París, no pudo participar directamente en la redacción de Helios pero manifestó vivo interés en la revista, con su palabra escrita estimuló al grupo de jóvenes fundadores, y mandó poemas suyos que contribuyeron mucho al prestigio del nuevo órgano cultural. La publicación de Helios fué motivo de una correspondencia copiosa entre Juan Ramón Jiménez y Darío. En otra carta a Darío, Juan Ramón habla de ciertos detalles económicos y manifiesta su deseo de pagar a buen precio la colaboración de Darío, teniendo en cuenta, sin duda, la perenne necesidad pecuniaria de su amigo. Benavente y Valle-Inclán, más prósperos, o menos despilfarradores, quizás, habían prometido colaboración gratuita. En esta carta, Juan Ramón habla también de sus colaboradores nombrando a tres de ellos: Agustín Querol, Martínez Sierra y Ramón Pérez de Ayala.

Los otros dos miembros del grupo fundador eran Pedro González Blanco, hermano de Andrés y de Edmundo González Blanco, 
y Carlos Navarro Lamarca. Todos eran españoles menos Carlos Navarro Lamarca, el único hispanoamericano de la dirección. Era éste un argentino acomodado que residía entonces en Madrid. Conocedor de la literatura de Inglaterra y de los Estados Unidos, a él le tocaba comentar obras escritas en inglés y traducir algunas de ellas. Fué traductor de Shakespeare.

Se vencieron todos los obstáculos administrativos y económicos y el primer número de Helios apareció, en abril de 1903. Bajo el título, en mayúsculas, se nombraban los asuntos comprendidos en el ámbito cultural de la revista: novela, poesía, teatro, música, pintura, escultura filosofía, historia, sociología, crítica, bibliografía, letras extranjeras. Pero lo más interesante es el sumario del contenido, pues en él figuran algunos de los nombres más ilustres de la literatura española del siglo xx. Lo transcribimos aquí:

\section{GENESIS}

Ramón Pérez de Ayala .......... La aldea lejana. Con motivo de "La aldea perdida".

Juan R. Jiménez ................ Arias tristes. Poesías.

Jacinto Benavente ............. La noche del sábado. Novela escénica. (Cuadro quinto.)

G. Martínez Sierra ............. Peregrino. Poema en prosa.

Emilio Sala ................ Origenes del color.

Pedro González-Blanco .......... iMargaritas Ad ...! Novela corta.

Carlos Navarro Lamarca .......... De Quincey. El vuelo de los sueños.

Santiago Rusiñol ................ Hojas de la vida.

Mauricio López-Roberts .......... El porvenir de Paco Tudela. (Capítullo x.)

Jorge Rodembach .............. Campanas de domingo. Poesías.

Mauricio Maeterlinck ............. Lo porvenir.

En la parte denominada "Crónica" hay una variedad de asuntos, la mayor parte de ellos brevemente comentados: opinión editorial, reseñas, notas sobre libros, tanto extranjeros como nacionales; una sección titulada "Fémina" de interés especial para mujeres, escrita por Margarita María de Monterrey, conocida después por sus traducciones de obras inglesas de carácter médico-sociológico. También se ve en la cubierta la advertencia siguiente: "Todos los trabajos que se publiquen en esta Revista escritos en lengua castellana, serán inéditos." En Helios se publicaron por primera vez obras 
que hoy en día se consideran como clásicas de la literatura hispánica. A los nombres de los escritores españoles ya mencionados, habría que agregar los de Unamuno, Azorín, Juan Valera, Antonio Machado, Manuel Machado, Serafín y Joaquín Alvarez Quintero, Salvador Rueda, para nombrar sólo algunos de los que más se leen en la actualidad. ${ }^{2}$

Juan Valera ya no era el árbitro literario de su tiempo, como lo había sido algunos años antes cuando publicó su famoso comentario sobre $A z u l$. Entre los españoles que escribían para Helios, Unamuno era, sin duda, el de más prestigio. Era mayor que los jóvenes que constituían el grupo fundador; su obra abarcaba varios géneros literarios; su pensamiento, mejor que ningún otro, representaba la ideología de la España renaciente; su recia personalidad ejercía una influencia honda en todos los que le rodeaban. En un artículo titulado "Vida y arte", publicado en el número de Helios para agosto de 1903, Unamuno se dirige a Antonio Machado, pero su mensaje valía para toda la generación de jóvenes españoles que entonces escribían. En la literatura no toleraba lo que no tuviera su raíz y origen en la vida. Exigía que los libros hablaran como los hombres y no los hombres como los libros. En su artículo embiste contra los poetas franceses que tanto se leían e imitaban en aquella época, pero que a él le parecían amanerados y ridículos:

...prefiero todo estampido bravío y fresco que nos pone a descubierto las entrañas de la vida, que no todas esas gaitas que acaban en los sonetos de Heredia o en las atrocidades de Baudelaire... no se debe tolerar que los anémicos traten de imponernos su estética, ni quieran hacer pasar por perfecciones sus soñolientas melopeas, sujetos que tengan amasado el. cuerpo con pus y el alna con envidia. ${ }^{3}$

Derribado ya y roto el ídolo del decadentismo francés, Unamuno le aconseja a Antonio Machado que profundice en la vida y la naturaleza españolas para encontrar su expresión:

Recorra, pues, la virgen selva española, y rasgue su costra y busque debajo de la sobrehaz calicostrada el agua que allí corre, agua de manantial soterraño. Huya, sobre todo, del "arte de arte", del arte de los artistas, hecho por ellos para ellos solos. 4 
La prueba de que Antonio Machado, Juan Ramón Jiménez, y otros jóvenes del grupo Helios no desoyeron el consejo de Unamuno está en la orientación que después tomó la poesía española. 5 Pasado el momento del modernismo superficial, la poesía española llegó a ser la expresión de lo hondo español y lo hondo universal. En esta transformación la influencia de Helios, sin duda, fué benéfica.

Aunque Helios era, propiamente dicho, una revista española, la participación hispanoamericana en su vida era activa e importante. Desde París, Darío siguió su desarrollo con gran interés. Poco después de que apareció el primer número, Dario le escribió a Juan Ramón Jiménez manifestándole su entusiasmo por la nueva revista y prometiéndole contribuciones propias. La carta, fechada el 12 de abril de 1903, dice en parte lo siguiente:

Mi querido poeta, Helios está preciosa y su artículo es noble, valiente, ise necesita valentía, allí...! -y admirablemente escrito-- Me afirma en mi creencia: todo poeta escribe bella prosa.

Dígame si alcanza -o hasta cuando alcanza- para el número próximo, algo, versos que le voy a mandar. O para el otro. Le enviaré lo primero de mi próximo volumen de versos. ${ }^{6}$

El entusiasmo de Darío no decreció, como lo demuestran cartas subsiguientes que escribió a Juan Ramón Jiménez. En una, de fecha 24 de julio de 1903, comunica su intención de enviarle versos nuevos que formarán parte de su próximo libro Cantos de vida y de esperanza. De Helios dice lo siguiente: "De U. veo en Helios cosas deliciosas. Helios es lo más brillante que hoy tiene la prensa española. Todos los redactores, cosa rara, valen."

En una carta del 20 de octubre de 1903 tiene otro elogio para los redactores: "Helios cada día mejor. Todos allí piensan, y eso es mucho"... En otra carta, del 20 de noviembre del mismo año, comenta que "Helios está lleno de distinción mental" y expresa la esperanza de que perdure su carácter elevado y serio.

Dario no se limitó a estimular con sus cartas al brillante grupo de escritores que dirigían esta alta empresa cultural sino que cumplió su promesa de mandar obras propias. En el número de Helios para febrero de 1904 se publicó por primera vez el famoso poema "A Roosevelt". Esta obra mejor, quizás, que ninguna otra 
publicada en Helios expresaba el sentimiento de solidaridad hispánica que en aquella época unía a todos los países de habla española. España e Hispanoamérica se sentían amenazados por un peligro común, y esta conciencia de la unidad de su destino histórico, muy acentuada desde el 1898, servía para afirmar los vínculos culturales que ya existían. Helios era una revista de carácter universal, lo cual se manifestaba en su vivo interés por la literatura, el arte y el pensamiento de todos los países y regiones del mundo, pero también era un puente, cultural y sentimental, que unía a Hispanoamérica con España.

Otro de los más conocidos de los poemas de Darío, que también apareció por primera vez en Helios, fué "Un soneto a Cervantes". Este poema, igual que "A Roosevelt", es la expresión de un hispanismo hondo $y$ sincero que no se deja ver en sus obras de épocas anteriores.

Dos de los libros en prosa de Darío fueron publicados en la época de Helios y están comentados en la revista. El primer número (abril de 1903) trae un artículo escrito por Juan Ramón Jiménez sobre Peregrinaciones, libro de ensayos e impresiones de viajes, que Darío publicó en París en 1901. En el número para enero de 1904, Martínez Sierra dedica un ensayo a La caravana pasa, libro formado por artículos que escribió Darío para La Nación de Buenos Aires, y que se imprimió, también en París, en 1903. Testimonio son estos ensayos críticos del gran prestigio que Darío había conquistado en España aún antes de que se publicara su libro de más puros antecedentes hispánicos, Cantos de vida y de esperanza. "Es indiscutible que Rubén Darío es el poeta más grande de los que actualmente escriben en castellano", comentó Juan Ramón Jiménez, emitiendo un juicio que se podría tomar como representativo de la opinión de su generación literaria.

No eran Darío y Carlos Navarro Lamarca los únicos hispanoamericanos que participaban en la vida de Helios. En el número para agosto de 1903 hay poesías de Manuel Ugarte, y crítica escrita por Carlos Arturo Torres. El de noviembre del mismo año tiene una sección titulada "Letras de América", dedicada enteramente a la publicación del artículo "Más allá" por el escritor venezolano José Gil Fortoul. En el número siguiente el colombiano Antonio José Restrepo escribe el artículo que constituye la sección 
"Letras de América". El título de su obra es "Fuego graneado". Artículos como éstos, sin duda contribuyeron a que los lectores españoles de Helios comenzaran a interesarse por autores hispanoamericanos y a que llegaran a conocerlos.

Manuel Ugarte, quien había iniciado su colaboración con un grupo de poemas, publicó en el número de febrero. de 1904 una obra en prosa titulada "Silueta de un crítico". Blanco-Fombona, conocido ya, tanto por su talento como por su cărácter violento, ${ }^{7}$ escribió un artículo que Rubén Darío se encargó de enviar a los redactores de Helios, y que apareció en el número de septiembre de 1903. Se titulaba "Las modernas danzas viejas" y elogiaba el arte de la bailarina Isidora Duncan, quien, a pesar de su nacionalidad norteamericana, había despertado la admiración del impulsivo venezolano.

Amado Nervo, atareado en aquella época con la redacción de otra revista de distinción cultural, La Revista Moderna de México, no escribió para Helios pero ya era conocido y admirado en España. Con motivo de la publicación de su libro El éxodo y las flores del camino, Juan Ramón Jiménez le dedicó un artículo en el número de Helios para octubre de 1903, en el cual alaba tanto la maestría técnica de Nervo como su fina sensibilidad poética.

Helios deja en el lector la impresión de un mundo hispánico que, como le había instado Unamuno, estaba descubriendo a su propia alma. Lejos, sin embargo, de cultivar un nacionalismo estrecho y conservador, abría las puertas para que los países de habla española pudieran recibir las corrientes intelectuales y artísticas más benéficas que venían desde afuera. Se publicaron artículos y notas sobre literatura inglesa, francesa, alemana, norteamericana, escandinava, rusa, neo-turca, albanesa. Se comentaba a Emerson, Schopenhauer, Nietzsche, Spencer, Wundt, la pintura en la Exposición Universal de París del año 1900, la música de Ricardo Strauss. Se extraía de otras culturas lo que pudiera enriquecer la propia, se acogía lo nuevo pero sin cortar las raíces que unían el presente al pasado. Hay en Helios páginas dedicadas a Góngora, a El Greco, a Larra y a Ganivet, en quienes la generación de Helios encontraba tantos antecedentes artísticos, espirituales e ideológicos.

La vida de una revista cultural suele ser efímera, y a Helios le sucedió lo mismo que a muchas otras valiosas revistas de breve existencia. Pero si murió, en el sentido de dejar de publicarse, no 
murió su influencia. Dió, en un momento muy decisivo, un gran impulso a una generación que aspiraba a llegar a las cumbres del mundo del arte y del espíritu. Es imposible calcular el alcance del estímulo y la orientación que dió, a los jóvenes de su época, pero como música que se pierde en el espacio, dejó, después de su muerte, sus finas vibraciones en la atmósfera espiritual de su siglo, vibraciones que todavía se pueden percibir.

DoNAID F. Fogelguist, University of California, Los Angeles, California.

\section{N O T A S}

1 Véase Alberto Ghiraldo, El archivo de Rubén Dario. Buenos Aires, Losada, 1945, pp. 14-15.

2. Aunque Galdós, Blasco Ibáñez y Pío Baroja no figuran entre sus colaboradores, Helios publicó estudios de sus obras: un artículo escrito por Martínez Sierra sobre Galdós (julio de 1903); reseñas sobre La Catedral y Cañas y barro de Blasco Ibáñez, y sobre El mayorazgo de Labraz de Pío Baroja.

3 Helios, agosto de 1903, p. 48.

4 Ibid., p. 50.

5 Antonio Machado daba ya claras muestras de su profundo talento poético. En Helios se publicaron algunos de sus poemas más hermosos. Para dar sólo algunos ejemplos citamos los versos iniciales de tres de éstos:

Llamó a mi corazón un claro día con un perfume de jazmín, el viento... La tarde está muriendo como un hogar humilde que se apaga... Desde el umbral del sueño me llamaron... Era la buena voz, la voz querida. -Dime: ¿vendrás conmigo a ver el alma?...

De Juan Ramón Jiménez se publicaron muchos poemas que después hubieron de aparecer en su tomo Arias tristes, libro cuyo delicado lirismo tanto agradó a Rubén Darío. Los versos siguientes bastarán para dar una idea del encanto que Darío encontró en los poemas de esta colección. 
Las noches de luna tienen una lumbre de azucena que inunda de paz el alma y de ensueño la tristeza.

-

y la música de esquilas

y la estrella solitaria y el humo que sube, todo tiembla al compás de la flauta.

6 Esta cita, así como las que siguen inmediatamente, son de cartas inéditas de Rubén Darío que forman parte del archivo personal de Juan Ramón Jiménez.

7 En la carta a Juan Ramón Jiménez que Darío mandó con el artículo de Blanco-Fombona, califica a éste de "aristocrático, brillante y fino poeta... y crítico un poquito apasionado y violento." 
